\title{
Nitrogen and Stem Development: A Puzzle Still to Be Solved
}

\author{
Lucas Anjos Souza ${ }^{1}$ and Rafael Tavares ${ }^{2 *}$ \\ ${ }^{1}$ Innovation Centre in Bioenergy and Grains, Goiano Federal Institute of Education, Science and Technology, Goiás, Brazil, \\ ${ }^{2}$ Department of Cell and Development Biology, John Innes Centre, Norwich Research Park, Norwich, United Kingdom
}

High crop yields are generally associated with high nitrogen $(N)$ fertilizer rates. A growing tendency that is urgently demanding the adoption of precision technologies that manage $\mathrm{N}$ more efficiently, combined with the advances of crop genetics to meet the needs of sustainable farm systems. Among the plant traits, stem architecture has been of paramount importance to enhance harvest index in the cereal crops. Nonetheless, the reduced stature also brought undesirable effect, such as poor $\mathrm{N}$-uptake, which has led to the overuse of $\mathrm{N}$ fertilizer. Therefore, a better understanding of how $\mathrm{N}$ signals modulate the initial and late stages of stem development might uncover novel semi-dwarf alleles without pleiotropic effects. Our attempt here is to review the most recent advances on this topic.

OPEN ACCESS

Edited by:

Surya Kant,

Agriculture Victoria,

Grains Innovation Park, Australia

Reviewed by:

Mamoru Okamoto,

University of Adelaide, Australia

Peter Hedden,

Rothamsted Research,

United Kingdom

*Correspondence:

Rafael Tavares

rafael.tavares@jic.ac.uk

Specialty section:

This article was submitted to Plant Nutrition,

a section of the journal

Frontiers in Plant Science

Received: 17 November 2020

Accepted: 25 January 2021

Published: 15 February 2021

Citation:

Souza LA and Tavares $R$ (2021) Nitrogen and Stem Development: $A$

Puzzle Still to Be Solved.

Front. Plant Sci. 12:630587.

doi: 10.3389/fp/s.2021.630587
Keywords: stem development, nitrogen use efficiency, internode elongation, high crop yield, nitrogen fertilizer

\section{INTRODUCTION}

To secure steadily growing global demand for food, agronomic practices have increasingly spurred more nitrogen $(\mathrm{N})$ fertilizer inputs to agricultural lands, leading not only to economic competitiveness between smallholder farmers, but also causing detrimental and pervasive impacts on the environment and climate (Cui et al., 2018; Kanter et al., 2019). Yet according to FAO (2019), N fertilizer consumption may continue its uptrend on global demand in the foreseeable future, rising by $2.6 \%$ to reach 111.5 teragrams ( $\mathrm{Tg}$ ) N by 2020/2022. In a world of climate volatility and over-farming, global food security is reliant on crop yield forecasting, which entails various elements of uncertainty and necessity that might lead to the over application of $\mathrm{N}$. At the farm level, for instance, lack of information about the bountiful supply of $\mathrm{N}$ available in the soil (Ladha et al., 2016; Yan et al., 2020) as well as precision agriculture (Omara et al., 2019) have led to uncertainties about $\mathrm{N}$ application rates by farmers (Lobell, 2007). Optimization of $\mathrm{N}$ dosage through site-specific best management practices (BMPs) has been proposed as the sustainable agriculture flagship to prevent run-off, which accounts for $67 \%$ of applied $\mathrm{N}$ fertilizer for cereal production worldwide (Raun and Johnson, 1999). On the other hand, the necessity for high $\mathrm{N}$ input has been a determinant factor, whereas the main cereal crops present a low nitrogen use efficiency (NUE) that demands considerable amounts of $\mathrm{N}$ for food production needs (Hawkesford and Griffiths, 2019). In the past, particularly in rice and wheat, breeders altered the growth response to $\mathrm{N}$ through the introduction of semi-dwarf genes to shorten the plant stature, the so-called Green Revolution (GR) varieties (Peng et al., 1999; Spielmeyer et al., 2002). As a result, they were able to reduce the lodging risk (i.e., bend or break the stem base), and to maximize yield potential in these modern varieties (Ortiz-Monasterio et al., 1997; Gooding et al., 2012); but as cited above, it has caused an unprecedented "domino effect" of $\mathrm{N}$ inputs, owing to the negative pleiotropic effects such 
as poorer N uptake (Li et al., 2018; Hawkesford and Griffiths, 2019; Wang et al., 2020; Wu et al., 2020).

Therefore, in parallel with BMPs and precision agriculture, the attenuation or elimination of the necessity of high $\mathrm{N}$ input must be targeted in the modern cereal crops. Although these high-yielding semi-dwarf varieties present an improved $\mathrm{N}$ utilization efficiency (i.e., grain yield per unit of $\mathrm{N}$ uptake) due to the direct response to fertilizer inputs without the effect of lodging, on the other hand, their $\mathrm{N}$ uptake efficiency (i.e., the capacity of the roots to acquire $\mathrm{N}$ from the soil) is negatively compromised by the dual-faceted impacts of gibberellin (GA) on plant height and $\mathrm{N}$ uptake ( $\mathrm{Li}$ et al., 2018; Wu et al., 2020). Despite recent contributions on $\mathrm{N}$ uptake should be pointed out (Feng et al., 2020; Rahikainen and Kangasjärvi, 2020), this mini-review attempts to summarize the current knowledge of how $\mathrm{N}$ regulates stem development, in order to encourage progress toward better semi-dwarfing alleles without undesirable effects in the future.

\section{NITRATE IS A DRIVING FORCE OF THE INITIAL STAGE OF STEM DEVELOPMENT}

All aerial organs are initiated at the apical dome, also known as shoot apical meristem (SAM). This region comprises dynamic and spatially functional zones that provide robustness and plasticity during the entire shoot ontogeny. Broadly speaking, at the tip of the SAM, the central zone (CZ) moves continuous daughter cells into the rib meristem (RM), where the stem's central core (pith) originates, and into the surrounding peripheral zone (PZ), which contributes to the stem epidermis and cortex (Gaillochet et al., 2015). Besides, the peripheral and central rib regions tandemly locate together, forming the rib zone (RZ), where proliferation and expansion give rise to the axial elongation in seed plants (McKim, 2019; Figure 1A). Thus, a sophisticated interconnection network between the zones through metabolites, non-cell-autonomous proteins, and phytohormones controls the size of the meristem and the rate of shoot organogenesis, ensuring a robust, plastic developmental spectrum (Tian et al., 2019).

This raises the question of whether there is a precise $\mathrm{N}$-led signaling pathway, or it is the spreading of $\mathrm{N}$ to the zones of the SAM that modulates RZ activity and stem elongation. Currently, novel pieces of evidence in Arabidopsis thaliana (hereafter called Arabidopsis) suggest the coexistence of dual $\mathrm{N}$ sensing within the SAM: a systemic and local signal. The systemic signal relies on the activation of transzeatin (tZ)-type cytokinin (CK) in roots, in response to $\mathrm{N}$ supply, and its translocation to the SAM via the xylem (Landrein et al., 2018; Poitout et al., 2018). Impairing CK allocation to the SAM through the cyp735a1 cyp735a2 double mutant, in which tZ-type CKs are severely reduced, exhibited a shortened inflorescence stem similar to that of abcg14, an important gene for CK transport (Kiba et al., 2013; Poitout et al., 2018). Notably, $t Z$ content may also positively influence glutamate/glutamine levels, which are known to promote stem elongation (Poitout et al., 2018). In contrast, the local signal comprises the action of nitrate itself entering into the SAM, where it is assimilated in the RZ and the organ boundary domain (B) through the nitrate assimilatory enzymes nitrate reductases (NIA1 and NIA2; Olas et al., 2019; Figure 1B).

The notion that these enzymes act as an $\mathrm{N}$-sensitive checkpoint in the SAM may be corroborated by the fact that their expression and activity are highly regulated to fine-tune the sensing and integration of carbon (C)/ $\mathrm{N}$ ratio (Klein et al., 2000; Park et al., 2011; Kim et al., 2018). The balance that is also determined by the tricarboxylic acid (TCA) cycle intermediate 2-oxoglutarate (2-OG), which is the major carbon skeleton in $\mathrm{N}$-assimilatory reactions for the synthesis of glutamate (Zheng, 2009; Huarancca Reyes et al., 2018). Interestingly, boundary domains exert a critical function in preserving stem elongation, whereas an ectopic expression of boundary genes [BLADE-ON-PETIOLE1 (BOP1/2)-Arabidopsis thaliana HOMEOBOX1 (ATH1)KNOTTED1-LIKE FROM A.THALIANA6 (KNAT6)] in the RZ causes growth defects (Khan et al., 2012a,b; Hepworth and Pautot, 2015). Recent work has shown that TGACG-motif binding- 1 and -4 (TGA1/4), two regulatory factors of the primary nitrate responses (Alvarez et al., 2014), interact and recruit BOP $1 / 2$ coactivators to the promoter of ATH 1 homeobox in Arabidopsis (Wang et al., 2019; Figure 1B). ATH1 is known to repress RZ proliferation, whereas ath 1-3 mutants displayed longer internodes than the wild-type control (Gómez-Mena and Sablowski, 2008). Scrutinizing the potential of this integration of TGA1/4 in $\mathrm{N}$ response and stem growth might open up new avenues for NUE.

Similar to other organs, stem development is regulated by the activity of two combined actions: cell division and expansion. In the most apical region of the RZ in both dicots and monocots [plus the intercalary meristem (IM) in grasses, the details are below] lies the active cell division which is regulated by GA (Sachs et al., 1959; Sachs, 1965; Serrano-Mislata et al., 2017). The notorious close interrelation between GA stimuli and N homeostasis at different regulatory levels in plants (David et al., 2016; Gras et al., 2018; Wang et al., 2020) creates a compelling logic to consider other semi-dwarfing alleles influencing stem elongation due to the negative pleiotropic effects. Strikingly, almost 67\% of GA-regulated genes in Arabidopsis require brassinosteroids (BRs; Bai et al., 2012). This high dependence reflects the interaction network of $\mathrm{BR}$ and GA at multiple levels in model plants that could be further explored for NUE. In rice, for instance, the brassinosteroid deficient mutant (osdwarf4-1) presented a slightly dwarfed stature and more erect leaves, which enhanced biomass production and grain yield, without extra fertilizer (Sakamoto et al., 2006).

Besides, recent studies have demonstrated the involvement of the microRNA miR396/growth regulating-factors (GRFs)/ GRF-interacting factors (GIFs) regulatory module in the interaction network of BR and GA signaling (Tang et al., 2018; Zhang et al., 2020). The overexpression of miR396 represses organ growth in Arabidopsis by repressing the activity of the targeted GRF and GIF genes (Rodriguez et al., 2010). Interestingly, the miR396 acts downstream of DELLA, the negative regulator of GA responses, and upstream of GA-induced cell-cycle genes 
A

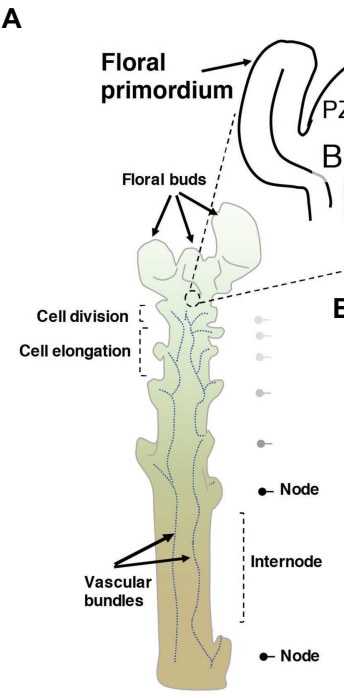

Arabidopsis inflorescence stem

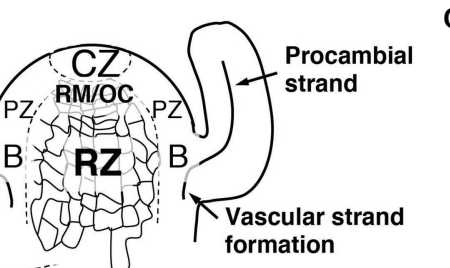

C $\underset{\text { plume }}{\text { primord }}$
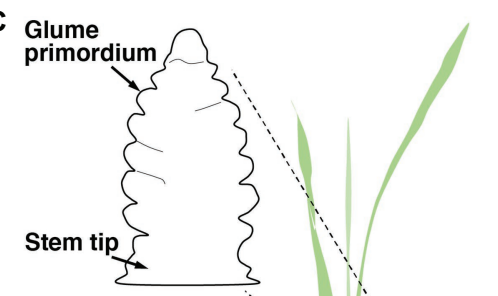

Bystemic

D
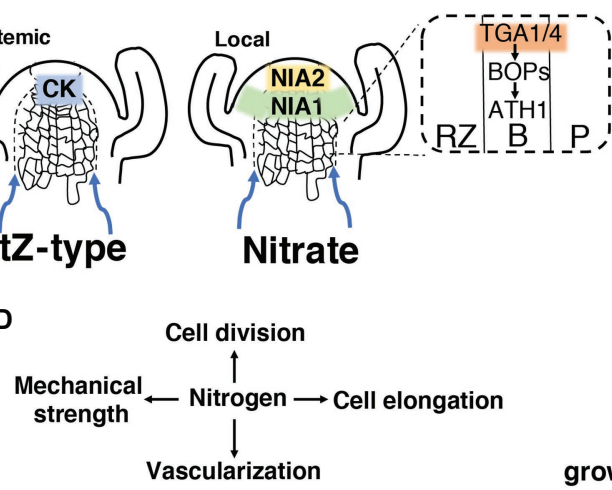

西
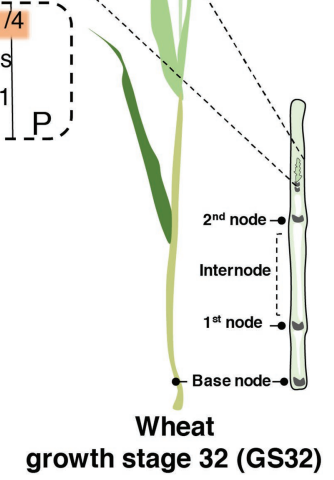

FIGURE 1 | How nitrogen (N) may modulate stem development. (A) Schematic illustration of Arabidopsis inflorescence stem showing the longitudinal section of the shoot apical meristem (SAM) and the meristematic zones. In detail, a representation of the oriented cell division in the rib zone (RZ). CZ, central zone; RM/OC, rib meristem/organizing centre; PZ, peripheral zone; B, organ boundary. (B) The dual nitrogen sensing within the shoot apex through a systemic root-to-shoot transport of the active cytokinin (CK) trans-zeatin (tZ), and the local sensing of nitrate through the nitrate reductase enzymes. In the dashed square, the two regulatory factors of the primary nitrate responses (TGA1/4) are highlighted, evidencing their involvement in the activation of the organ boundary genes. Blue arrows show the direction of root-to-shoot transportation. (C) Schematic illustration of wheat showing the growth stage 32 (GS32) based on Zadoks et al. (1974). In wheat, most N is taken up during the stem elongation phase (GS30-GS37) until the flowering stage. On the right, the longitudinal section of the nodes and internodes, and the floret initiation at this stage. (D) A simplified scheme of the central role of $\mathrm{N}$ in the regulation of the four different aspects of stem development.

for the control of stem elongation in rice (Lu et al., 2020). Conversely, more recently, the miR396e and miR396f (miR396ef) rice mutants showed an increased grain yield under nitrogendeficient conditions (Zhang et al., 2020). Future studies addressing the cross-talk between $\mathrm{N}$ and BR signaling and the miR396GRFs module in the RZ may disclose a new perspective on $\mathrm{N}$-driven stem elongation.

At the early stages of stem development, the establishment of a vascular pattern is an important aspect. New vascular strands are initiated by the canalization of auxin flow from new primordia toward a pre-existing vascular network (Scarpella, 2017). As auxin signaling is inhibited in the RM region in dicotyledons, these new vascular networks are initiated at the boundary between the peripheral and the central regions of the RZ (Banasiak et al., 2019). Reflecting on the importance of auxin in controlling the formation of veins and their connections, recent work revealed the uniform expression of TRANSPORT INHIBITOR RESPONSE1 (TIR1)/AUXINSIGNALING F-BOX (AFB) proteins in the SAM (Prigge et al., 2020). AFB3 is directly regulated by nitrate (Vidal et al., 2010) and potentially regulates the direction of auxin transport during stem vascularization (Wulf et al., 2019). Besides, two master regulators of primary nitrate response, NIN-LIKE PROTEIN6/7 (NPL6 and NPL7) are expressed in the SAM and adjacent PZ (Olas et al., 2019). Notably, recent findings connect NLP7 with the $\mathrm{Ca}^{2+}$-sensor protein kinases (CPKs) to orchestrate nutrient-growth regulatory networks (Liu et al., 2017). Although CPK28 is not part of the subgroup III, of which the genes are nitrate-responsive (e.g., CPK10, CPK30 and CPK32), it controls stem elongation and vascular development in Arabidopsis (Matschi et al., 2013). Further studies will be required to scrutinize in more detail their roles in stem development.

Moreover, once a stem starts growing (i.e., N-demanding tissue), vascularisation plays an essential role in the sourceto-sink N remobilization (Fernie et al., 2020). As such, nitrate transporters on major and minor veins facilitate $\mathrm{N}$ allocation to fast-growing sinks, optimizing plant growth in $\mathrm{N}$-sufficient and $\mathrm{N}$-deficient conditions (Tegeder and Masclaux-Daubresse, 2018; Chen et al., 2020). One example is the nitrate transporter1/ peptide transporter family (osnpf2.2) rice mutants, which showed growth retardation and abnormal vasculature (Li et al., 2015). Apart from inorganic $\mathrm{N}$, organic $\mathrm{N}$ might also be critical for stem development. For instance, polyamines (putrescine, spermidine and spermine) are aliphatic amines that act as growth regulators in plant growth and development (Chen et al., 2019). It is worthwhile to investigate the increase of polyamine content in nitrate and ammonium-grown plants (Garnica et al., 2009; Paschalidis et al., 2019), whereas the ACAULIS5/THICKVEIN (ACL5/TKV) protein, a thermospermine synthase, is also involved in stem elongation and vascularization in plants (Hanzawa, 2000; Clay and Nelson, 2005; Vera-Sirera et al., 2015). 


\section{N SIGNALING IN THE LATER STAGES OF STEM DEVELOPMENT: INTERNODE ELONGATION AND LIGNIFICATION}

In dicot plants with a rosette habit such as Arabidopsis, radish and cabbage, among other species, the compressed vegetative internodes shift to an acropetal expansion after the reproductive transition. In contrast, in monocots, particularly grasses, vegetative internodes are promoted by intercalary meristems (IMs), located at the base of each internode (Figure 1C). After an increased mitotic activity within the IMs, the cells are displaced upward, entering various zones of expansion and lengthening each succeeding internode until the heading stage, which later gives rise to the grain-laden inflorescence (McKim, 2020).

Thus, both RZ and internodal regions exhibit various sorts of cells differing in their states of proliferation, growth, and differentiation. Regarding cell growth, for instance, a high level of endopolyploidy (i.e., modified cell cycle without cytokinesis) occurs in pith cells following organ maturation in Arabidopsis and maize (Jacqmard et al., 1999, 2003; Li et al., 2019). This ties in with a recent study showing that nitrate signaling regulates shoot growth by controlling endoreduplication through the upregulation of a key cell cycle regulatory gene $L G O$, a known cyclin-dependent kinase (CDK) inhibitor (Moreno et al., 2020). Given that nitrate regulates LGO-mediated endoreduplication and cell expansion in Arabidopsis, it is reasonable to speculate whether such modulation is also present within the RZ and internodal regions of cereal and bioenergy crops, which may also explain the N-responsive stem elongation of such crops (Euring et al., 2014; Zeng et al., 2020).

In addition, cell proliferation and expansion strictly depend on the mechanical properties of primary cell walls (CW). Differences in the expression of CW-related genes and CW composition have been observed during stem elongation (Hall et al., 2013; Hall and Ellis, 2013). A detailed study of CW composition and the dynamic and mechanical properties of the Arabidopsis inflorescence stem suggested that changes in the pectin structure, dynamism and mobility lead to weak pectin-cellulose interaction, being likely the main factors leading to the wall extensibility in fast-growing regions (Phyo et al., 2017). Indeed, CW analysis of the upper region of the stem (high growth intensity) presented higher pectin and lower amounts of xyloglucan $(\mathrm{XyG})$ and (lower) cellulose contents (Phyo et al., 2017). Of interest, in type I-CW, in which XyG is the most abundant hemicellulose, a very recent study of Arabidopsis showed that the cell wall-related gene xyloglucan endotransglucosylases-9 (XTH9), which is highly expressed in the shoot apices and might contribute to cell elongation in the stem (Hyodo et al., 2003), is regulated by the nitrate signaling pathway (Xu and Cai, 2019).

Moreover, although the specific mechanisms are still to be understood, novel evidence suggests that cellulose content is modulated in response to $\mathrm{N}$ status in Arabidopsis and rice (Landi and Esposito, 2017; Zhang et al., 2017). Yet, in grassspecific type-II CW, different inorganic $\mathrm{N}$ forms, such as nitrate and ammonium, may modify the chemical structure of pectins and hemicelluloses (Podgórska et al., 2017). The CW properties are thereby dynamically regulated to allow sufficient nutrients to reach demanding organs, as well as to allow cell expansion prior to growth cessation, a tightly regulated process that is accompanied by N status (Głazowska et al., 2019).

Stem maturation is followed by secondary cell wall production and lignification (Barros et al., 2015), which confer stem properties such as length, flexibility and strength, and are tightly regulated to prevent bending and breaking which lead to crop lodging. Interestingly, recent work showed that high $\mathrm{N}$ availability substantially reduces the $\mathrm{H}, \mathrm{G}$ and $\mathrm{S}$ monolignol precursors (p-coumaryl alcohol, coniferyl alcohol, and sinapyl alcohol, respectively) of lignin, and hence, the total lignin content in the shoot of maize seedlings (Sun et al., 2018). The authors elegantly demonstrated that the miR528, a monocot-specific miRNA expressed in vascular tissues, is upregulated by $\mathrm{N}$ supply, leading to the repression of ZmLACCASE3 (ZmLAC3) and ZmLACCASE5 ( $Z m L A C 5)$, oxidative enzymes involved in lignin polymerization (Schuetz et al., 2014), that will ultimately make such plants more prone to lodging under high $\mathrm{N}$ supply (Sun et al., 2018). Likewise, a high $\mathrm{N}$ supply increases the lodging index in two varieties of japonica rice, owing to the significant reduction of cellulose and lignin contents (Zhang et al., 2017). Yet, CW profiles of Brachypodium supplied with different types of $\mathrm{N}$ source (ammonium and nitrate) showed that nitrate-fed plants were prone to less lignification rates than those from ammonium-fed plants, suggesting that the $\mathrm{CW}$ architecture is modulated according to the uptake and assimilation of different $\mathrm{N}$ form through the cross-talk between $\mathrm{N}$ metabolism and CW synthesis (Głazowska et al., 2019).

These recent results demonstrated that cell expansion (plastic growth) and CW lignification are strictly influenced by $\mathrm{N}$ availability. A key mechanism that might be coordinating these adaptive changes is the cell wall integrity (CWI) maintenance mechanism that is conserved in both monocot and dicot plants (Bacete and Hamann, 2020). Intriguingly, recent results from genetic analyses suggest that NIA1 and NIA2 act downstream of THESEUS1 (THE1), a surface CW sensor, in initiating CW damage responses (Gigli-Bisceglia et al., 2018). THE1 is expressed in elongating cells and in vascular tissues in Arabidopsis. Among its target genes, various $\mathrm{CW}$-related proteins involved in loosening and stiffening are regulated, such as extensins, peroxidase 59 and expansin 1 (Hématy et al., 2007). Thus, the CWI mechanism might be a regulator of plant growth according to $\mathrm{N}$ status from the environment. Future investigations may unveil this intricate action of $\mathrm{N}$ into CWI signaling, which might be a potential target for heightening NUE in crops.

\section{CONCLUSION AND PERSPECTIVES}

Although a shorter stature and stem sturdiness have revolutionized world cereal production in the last 50 years, the adoption of the original semi-dwarfing alleles has also brought the necessity for an increasing amount of $\mathrm{N}$ fertilizer due to the negative pleiotropic effects. Although several studies 
have been carried out to understand the genetic basis of $\mathrm{N}$ assimilation, curiously, very little attention has been paid so far to how environmental $\mathrm{N}$ signals modulate $\mathrm{RZ}$ activity and stem development, mainly in monocot plants (Figure 1D). With the advent of recent technical advances in quantitative imaging (Serrano-Mislata et al., 2017), bio-imaging (de Reuille et al., 2015), and biophysical techniques (Phyo et al., 2017; Shah et al., 2017), along with developmental genetics, a clear picture of molecular, cellular and mechanical mechanisms of stem growth is increasingly emerging. Understanding these developmental mechanisms will allow more genetic tools to alter stem architecture and eliminate the root cause of high $\mathrm{N}$ need in modern semi-dwarfing varieties in order to increase productivity and decrease environmental pollution.

\section{REFERENCES}

Alvarez, J. M., Riveras, E., Vidal, E. A., Gras, D. E., Contreras-López, O., Tamayo, K. P., et al. (2014). Systems approach identifies TGA1 and TGA4 transcription factors as important regulatory components of the nitrate response of Arabidopsis thaliana roots. Plant J. 80, 1-13. doi: 10.1111/ tpj. 12618

Bacete, L., and Hamann, T. (2020). The role of mechanoperception in plant cell wall integrity maintenance. Plan. Theory 9:574. doi: 10.3390/plants9050574

Bai, M. Y., Shang, J. X., Oh, E., Fan, M., Bai, Y., Zentella, R., et al. (2012). Brassinosteroid, gibberellin and phytochrome impinge on a common transcription module in Arabidopsis. Nat. Cell Biol. 14, 810-817. doi: 10.1038/ ncb2546

Banasiak, A., Biedroń, M., Dolzblasz, A., and Berezowski, M. A. (2019). Ontogenetic changes in auxin biosynthesis and distribution determine the organogenic activity of the shoot apical meristem in pin1 mutants. Int. J. Mol. Sci. 20:180. doi: 10.3390/ijms20010180

Barros, J., Serk, H., Granlund, I., and Pesquet, E. (2015). The cell biology of lignification in higher plants. Ann. Bot. 115, 1053-1074. doi: 10.1093/aob/ mcv046

Chen, K. E., Chen, H. Y., Tseng, C. S., and Tsay, Y. F. (2020). Improving nitrogen use efficiency by manipulating nitrate remobilization in plants. Nat. Plants 6, 1126-1135. doi: 10.1038/s41477-020-00758-0

Chen, D., Shao, Q., Yin, L., Younis, A., and Zheng, B. (2019). Polyamine function in plants: metabolism, regulation on development, and roles in abiotic stress responses. Front. Plant Sci. 9:1945. doi: 10.3389/fpls.2018.01945

Clay, N. K., and Nelson, T. (2005). Arabidopsis thickvein mutation affects vein thickness and organ vascularization, and resides in a provascular cell-specific spermine synthase involved in vein definition and in polar auxin transport. Plant Physiol. 138, 767-777. doi: 10.1104/pp.104.055756

Cui, Z., Zhang, H., Chen, X., Zhang, C., Ma, W., Huang, C., et al. (2018). Pursuing sustainable productivity with millions of smallholder farmers. Nature 555, 363-366. doi: 10.1038/nature25785

David, L. C., Berquin, P., Kanno, Y., Seo, M., Daniel-Vedele, F., and Ferrario-Méry, S. (2016). N availability modulates the role of NPF3.1, a gibberellin transporter, in GA-mediated phenotypes in Arabidopsis. Planta 244, 1315-1328. doi: 10.1007/s00425-016-2588-1

de Reuille, P. B., Routier-Kierzkowska, A. L., Kierzkowski, D., Bassel, G. W., Schüpbach, T., Tauriello, G., et al. (2015). MorphoGraphX: a platform for quantifying morphogenesis in 4D. elife 4:05864. doi: 10.7554/eLife.05864

Euring, D., Bai, H., Janz, D., and Polle, A. (2014). Nitrogen-driven stem elongation in poplar is linked with wood modification and gene clusters for stress, photosynthesis and cell wall formation. BMC Plant Biol. 14:391. doi: 10.1186/ s12870-014-0391-3

FAO (2019). World fertilizer trends and outlook to 2022. Available at: http://www. fao.org/3/ca6746en/CA6746EN.pdf?eloutlink=imf2fao (Accessed September 04, 2020).

Feng, H., Fan, X., Miller, A. J., and Xu, G. (2020). Plant nitrogen uptake and assimilation: regulation of cellular $\mathrm{pH}$ homeostasis. J. Exp. Bot. 71, 4380-4392. doi: $10.1093 / \mathrm{jxb} / \mathrm{eraa} 150$

\section{AUTHOR CONTRIBUTIONS}

LAS and RT conceived, discussed, organized and contributed equally for writing and reviewing all this manuscript. All authors contributed to the article and approved the submitted version.

\section{FUNDING}

We would like to thank the Brazilian funding agencies CAPES, CNPq, FAPEG, the Goiano Federal Institute of Education, Science and Technology to LAS, and the Marie SklodowskaCurie Individual Fellowship (MSCA-IF-2018; 838718 to RT) for their financial support.

Fernie, A. R., Bachem, C. W. B., Helariutta, Y., Neuhaus, H. E., Prat, S., Ruan, Y. L., et al. (2020). Synchronization of developmental, molecular and metabolic aspects of source-sink interactions. Nat. Plants 6, 55-66. doi: 10.1038/s41477-020-0590-x

Gaillochet, C., Daum, G., and Lohmann, J. U. (2015). O cell, where art thou? The mechanisms of shoot meristem patterning. Curr. Opin. Plant Biol. 23, 91-97. doi: 10.1016/j.pbi.2014.11.002

Garnica, M., Houdusse, F., Claude Yvin, J., and Garcia-Mina, J. M. (2009). Nitrate supply induces changes in polyamine content and ethylene production in wheat plants grown with ammonium. J. Plant Physiol. 166, 363-374. doi: 10.1016/j.jplph.2008.06.008

Gigli-Bisceglia, N., Engelsdorf, T., Strnad, M., Vaahtera, L., Khan, G. A., Jamoune, A., et al. (2018). Cell wall integrity modulates Arabidopsis thaliana cell cycle gene expression in a cytokinin-and nitrate reductase-dependent manner. Dev. Dent. 145:dev166678. doi: 10.1242/dev.166678

Głazowska, S., Baldwin, L., Mravec, J., Bukh, C., Fangel, J. U., Willats, W. G., et al. (2019). The source of inorganic nitrogen has distinct effects on cell wall composition in Brachypodium distachyon. J. Exp. Bot. 70, 6461-6473. doi: $10.1093 /$ jxb/erz388

Gómez-Mena, C., and Sablowski, R. (2008). Arabidopsis thaliana Homeobox Genel establishes the basal boundaries of shoot organs and controls stem growth. Plant Cell 20, 2059-2072. doi: 10.1105/tpc.108.059188

Gooding, M. J., Addisu, M., Uppal, R. K., Snape, J. W., and Jones, H. E. (2012). Effect of wheat dwarfing genes on nitrogen-use efficiency. J. Agric. Sci. 150, 3-22. doi: 10.1017/S0021859611000414

Gras, D. E., Vidal, E. A., Undurraga, S. F., Riveras, E., Moreno, S., Dominguez-Figueroa, J., et al. (2018). SMZ/SNZ and gibberellin signaling are required for nitrate-elicited delay of flowering time in Arabidopsis thaliana. J. Exp. Bot. 69, 619-631. doi: 10.1093/jxb/erx423

Hall, H. C., Cheung, J., and Ellis, B. E. (2013). Immunoprofiling reveals unique cell-specific patterns of wall epitopes in the expanding Arabidopsis stem. Plant J. 74, 134-147. doi: 10.1111/tpj.12111

Hall, H., and Ellis, B. (2013). Transcriptional programming during cell wall maturation in the expanding Arabidopsis stem. BMC Plant Biol. 13:14. doi: 10.1186/1471-2229-13-14

Hanzawa, Y. (2000). ACAULIS5, an Arabidopsis gene required for stem elongation, encodes a spermine synthase. EMBO J. 19, 4248-4256. doi: 10.1093/emboj/19.16.4248

Hawkesford, M. J., and Griffiths, S. (2019). Exploiting genetic variation in nitrogen use efficiency for cereal crop improvement. Curr. Opin. Plant Biol. 49, 35-42. doi: 10.1016/j.pbi.2019.05.003

Hématy, K., Sado, P. E., Van Tuinen, A., Rochange, S., Desnos, T., Balzergue, S., et al. (2007). A receptor-like kinase mediates the response of Arabidopsis cells to the inhibition of cellulose synthesis. Curr. Biol. 17, 922-931. doi: 10.1016/j.cub.2007.05.018

Hepworth, S. R., and Pautot, V. A. (2015). Beyond the divide: boundaries for patterning and stem cell regulation in plants. Front. Plant Sci. 6:1052. doi: 10.3389/fpls.2015.01052

Huarancca Reyes, T., Scartazza, A., Pompeiano, A., Ciurli, A., Lu, Y., Guglielminetti, L., et al. (2018). Nitrate reductase modulation in response 
to changes in $\mathrm{c} / \mathrm{n}$ balance and nitrogen source in Arabidopsis. Plant Cell Physiol. 59, 1248-1254. doi: 10.1093/pcp/pcy065.

Hyodo, H., Yamakawa, S., Takeda, Y., Tsuduki, M., Yokota, A., Nishitani, K., et al. (2003). Active gene expression of a xyloglucan endotransglucosylase/ hydrolase gene, XTH9, in inflorescence apices is related to cell elongation in Arabidopsis thaliana. Plant Mol. Biol. 52, 473-482. doi: 10.1023/A:1023904217641

Jacqmard, A., De Veylder, L., Segers, G., De Almeida Engler, J., Bernier, G., Van Montagu, M., et al. (1999). Expression of CKS1At in Arabidopsis thaliana indicates a role for the protein in both the mitotic and the endoreduplication cycle. Planta 207, 496-504. doi: 10.1007/s004250050509

Jacqmard, A., Gadisseur, I., and Bernier, G. (2003). Cell division and morphological changes in the shoot apex of Arabidopsis thaliana during floral transition. Ann. Bot. 91, 571-576. doi: 10.1093/aob/mcg053

Kanter, D. R., Bell, A. R., and McDermid, S. S. (2019). Precision agriculture for smallholder nitrogen management. One Earth 1, 281-284. doi: 10.1016/j. oneear.2019.10.015

Khan, M., Tabb, P., and Hepworth, S. R. (2012a). BLADE-ON-PETIOLE1 and 2 regulate Arabidopsis inflorescence architecture in conjunction with homeobox genes KNAT6 and ATH1. Plant Signal. Behav. 7, 788-792. doi: 10.4161/ psb.20599

Khan, M., Xu, M., Murmu, J., Tabb, P., Liu, Y., Storey, K., et al. (2012b). Antagonistic interaction of BLADE-ON-PETIOLE1 and 2 with BREVIPEDICELLUS and PENNYWISE regulates Arabidopsis inflorescence architecture. Plant Physiol. 158, 946-960. doi: 10.1104/pp.111.188573

Kiba, T., Takei, K., Kojima, M., and Sakakibara, H. (2013). Side-chain modification of Cytokinins controls shoot growth in Arabidopsis. Dev. Cell 27, 452-461. doi: 10.1016/j.devcel.2013.10.004

Kim, J. Y., Park, B. S., Park, S. W., Lee, H. Y., Song, J. T., and Seo, H. S. (2018). Nitrate reductases are relocalized to the nucleus by atSIZ1 and their levels are negatively regulated by COP1 and ammonium. Int. J. Mol. Sci. 19, 1-15. doi: 10.3390/ijms19041202

Klein, D., Morcuende, R., Stitt, M., and Krapp, A. (2000). Regulation of nitrate reductase expression in leaves by nitrate and nitrogen metabolism is completely overridden when sugars fall below a critical level. Plant Cell Environ. 23, 863-871. doi: 10.1046/j.1365-3040.2000.00593.x

Ladha, J. K., Tirol-Padre, A., Reddy, C. K., Cassman, K. G., Verma, S., Powlson, D. S., et al. (2016). Global nitrogen budgets in cereals: a 50-year assessment for maize, rice, and wheat production systems. Sci. Rep. 6, 1-9. doi: 10.1038/srep 19355

Landi, S., and Esposito, S. (2017). Nitrate uptake affects cell wall synthesis and modeling. Front. Plant Sci. 8:1376. doi: 10.3389/fpls.2017.01376

Landrein, B., Formosa-Jordan, P., Malivert, A., Schuster, C., Melnyk, C. W., Yang, W., et al. (2018). Nitrate modulates stem cell dynamics in Arabidopsis shoot meristems through cytokinins. Proc. Natl. Acad. Sci. U. S. A. 115, 1382-1387. doi: 10.1073/pnas.1718670115

Li, S., Liu, L., Li, T., Lan, T., Wang, Y., Zhang, Z., et al. (2019). The distribution pattern of endopolyploidy in maize. Theor. Appl. Genet. 132, 1487-1503. doi: 10.1007/s00122-019-03294-4

Li, Y., Ouyang, J., Wang, Y. Y., Hu, R., Xia, K., Duan, J., et al. (2015). Disruption of the rice nitrate transporter OsNPF2.2 hinders root-to-shoot nitrate transport and vascular development. Sci. Rep. 5:9635. doi: 10.1038/srep09635

Li, S., Tian, Y., Wu, K., Ye, Y., Yu, J., Zhang, J., et al. (2018). Modulating plant growth-metabolism coordination for sustainable agriculture. Nature 560, 595-600. doi: 10.1038/s41586-018-0415-5

Liu, K. H., Niu, Y., Konishi, M., Wu, Y., Du, H., Sun Chung, H., et al. (2017). Discovery of nitrate-CPK-NLP signalling in central nutrient-growth networks. Nature 545, 311-316. doi: 10.1038/nature22077.

Lobell, D. B. (2007). The cost of uncertainty for nitrogen fertilizer management: a sensitivity analysis. F. Crop. Res. 100, 210-217. doi: 10.1016/j.fcr.2006.07.007

Lu, Y., Feng, Z., Meng, Y., Bian, L., Xie, H., Mysore, K. S., et al. (2020). SLENDER RICE1 and Oryza sativa INDETERMINATE DOMAIN2 regulating OsmiR396 are involved in stem Elongation1. Plant Physiol. 182, 2213-2227. doi: 10.1104/PP.19.01008

Matschi, S., Werner, S., Schulze, W. X., Legen, J., Hilger, H. H., and Romeis, T. (2013). Function of calcium-dependent protein kinase CPK28 of Arabidopsis thaliana in plant stem elongation and vascular development. Plant J. 73, 883-896. doi: $10.1111 /$ tpj.12090

McKim, S. M. (2019). How plants grow up. J. Integr. Plant Biol. 61, 257-277. doi: $10.1111 /$ jipb. 12786
McKim, S. M. (2020). Moving on up - controlling internode growth. New Phytol. 226, 672-678. doi: 10.1111/nph.16439

Moreno, S., Canales, J., Hong, L., Robinson, D., Roeder, A. H. K., and Gutiérrez, R. A. (2020). Nitrate defines shoot size through compensatory roles for Endoreplication and cell division in Arabidopsis thaliana. Curr. Biol. 30, 1988-2000.e3. doi: 10.1016/j.cub.2020.03.036

Olas, J. J., Van Dingenen, J., Abel, C., Działo, M. A., Feil, R., Krapp, A., et al. (2019). Nitrate acts at the Arabidopsis thaliana shoot apical meristem to regulate flowering time. New Phytol. 223, 814-827. doi: 10.1111/nph.15812

Omara, P., Aula, L., Oyebiyi, F., and Raun, W. R. (2019). World cereal nitrogen use efficiency trends: review and current knowledge. Agrosystems. Geosci. Environ. 2, 1-8. doi: 10.2134/age2018.10.0045

Ortiz-Monasterio, R., I, J., Sayre, K. D., Rajaram, S., and McMahon, M. (1997). Genetic progress in wheat yield and nitrogen use efficiency under four nitrogen rates. Crop Sci. 37, 898-904. doi: 10.2135/cropsci1997.0011183X003700030033x.

Park, B. S., Song, J. T., and Seo, H. S. (2011). Arabidopsis nitrate reductase activity is stimulated by the E3 SUMO ligase AtSIZ1. Nat. Commun. 2:400. doi: $10.1038 /$ ncomms 1408

Paschalidis, K., Tsaniklidis, G., Wang, B. Q., Delis, C., Trantas, E., Loulakakis, K., et al. (2019). The interplay among polyamines and nitrogen in plant stress responses. Plan. Theory 8, 1-12. doi: 10.3390/plants8090315

Peng, J., Richards, D. E., Hartley, N. M., Murphy, G. P., Devos, K. M., Flintham, J. E., et al. (1999). "Green revolution" genes encode mutant gibberellin response modulators. Nature 400, 256-261. doi: 10.1038/22307.

Phyo, P., Wang, T., Kiemle, S. N., O’Neill, H., Pingali, S. V., Hong, M., et al. (2017). Gradients in wall mechanics and polysaccharides along growing inflorescence stems. Plant Physiol. 175, 1593-1607. doi: 10.1104/pp.17.01270.

Podgórska, A., Burian, M., Gieczewska, K., Ostaszewska-Bugajska, M., Zebrowski, J., Solecka, D., et al. (2017). Altered cell wall plasticity can restrict plant growth under ammonium nutrition. Front. Plant Sci. 8:1344. doi: 10.3389/ fpls.2017.01344

Poitout, A., Crabos, A., Petř́k, I., Novák, O., Krouk, G., Lacombe, B., et al. (2018). Responses to systemic nitrogen signaling in Arabidopsis roots involve trans-zeatin in shoots. Plant Cell 30, 1243-1257. doi: 10.1105/tpc.18.00011.

Prigge, M. J., Platre, M., Kadakia, N., Zhang, Y., Greenham, K., Szutu, W., et al. (2020). Genetic analysis of the Arabidopsis TIR1/AFB auxin receptors reveals both overlapping and specialized functions. elife 9, 1-28. doi: 10.7554/ eLife. 54740

Rahikainen, M., and Kangasjärvi, S. (2020). On the roots of nitrogen uptake. New Phytol. 228, 802-804. doi: 10.1111/nph.16803

Raun, W. R., and Johnson, G. V. (1999). Improving nitrogen use efficiency for cereal production. Agron. J. 91, 357-363. doi: 10.2134/agronj1999.000219620 09100030001x

Rodriguez, R. E., Mecchia, M. A., Debernardi, J. M., Schommer, C., Weigel, D., and Palatnik, J. F. (2010). Control of cell proliferation in Arabidopsis thaliana by microRNA miR396. Development 137, 103-112. doi: 10.1242/dev.043067

Sachs, R. M. (1965). Stem elongation. Annu. Rev. Plant Physiol. 16, 73-95.

Sachs, R., Bretz, C., and Lang, A. (1959). Cell division and gibberellic acid. Exp. Cell Res. 18, 230-244.

Sakamoto, T., Morinaka, Y., Ohnishi, T., Sunohara, H., Fujioka, S., Ueguchi-Tanaka, M., et al. (2006). Erect leaves caused by brassinosteroid deficiency increase biomass production and grain yield in rice. Nat. Biotechnol. 24, 105-109. doi: 10.1038/nbt1173.

Scarpella, E. (2017). The logic of plant vascular patterning. Polarity, continuity and plasticity in the formation of the veins and of their networks. Curr. Opin. Genet. Dev. 45, 34-43. doi: 10.1016/j.gde.2017.02.009

Schuetz, M., Benske, A., Smith, R. A., Watanabe, Y., Tobimatsu, Y., Ralph, J., et al. (2014). Laccases direct lignification in the discrete secondary cell wall domains of protoxylem. Plant Physiol. 166, 798-807. doi: 10.1104/pp.114.245597.

Serrano-Mislata, A., Bencivenga, S., Bush, M., Schiessl, K., Boden, S., and Sablowski, R. (2017). DELLA genes restrict inflorescence meristem function independently of plant height. Nat. Plants 3, 749-754. doi: 10.1038/ s41477-017-0003-y.

Shah, D. U., Reynolds, T. P. S., and Ramage, M. H. (2017). The strength of plants: theory and experimental methods to measure the mechanical properties of stems. J. Exp. Bot. 68, 4497-4516. doi: 10.1093/jxb/erx245

Spielmeyer, W., Ellis, M. H., and Chandler, P. M. (2002). Semidwarf (sd-1), "green revolution" rice, contains a defective gibberellin 20-oxidase gene. Proc. Natl. Acad. Sci. U. S. A. 99, 9043-9048. doi: 10.1073/pnas.132266399 
Sun, Q., Liu, X., Yang, J., Liu, W., Du, Q., Wang, H., et al. (2018). MicroRNA528 affects lodging resistance of maize by regulating lignin biosynthesis under nitrogen-luxury conditions. Mol. Plant 11, 806-814. doi: 10.1016/j.molp.2018.03.013.

Tang, Y., Liu, H., Guo, S., Wang, B., Li, Z., Chong, K., et al. (2018). OsmiR396d affects gibberellin and brassinosteroid signaling to regulate plant architecture in rice. Plant Physiol. 176, 946-959. doi: 10.1104/pp.17.00964.

Tegeder, M., and Masclaux-Daubresse, C. (2018). Source and sink mechanisms of nitrogen transport and use. New Phytol. 217, 35-53. doi: 10.1111/nph.14876

Tian, C., Wang, Y., Yu, H., He, J., Wang, J., Shi, B., et al. (2019). A gene expression map of shoot domains reveals regulatory mechanisms. Nat. Commun. 10, 1-12. doi: 10.1038/s41467-018-08083-z.

Vera-Sirera, F., De Rybel, B., Úrbez, C., Kouklas, E., Pesquera, M., Álvarez-Mahecha, J. C., et al. (2015). A bHLH-based feedback loop restricts vascular cell proliferation in plants. Dev. Cell 35, 432-443. doi: 10.1016/j. devcel.2015.10.022.

Vidal, E. A., Araus, V., Lu, C., Parry, G., Green, P. J., Coruzzi, G. M., et al. (2010). Nitrate-responsive miR393/AFB3 regulatory module controls root system architecture in Arabidopsis thaliana. Proc. Natl. Acad. Sci. U. S. A. 107, 4477-4482. doi: 10.1073/pnas.0909571107.

Wang, Y., Salasini, B. C., Khan, M., Devi, B., Bush, M., Subramaniam, R., et al. (2019). Clade i tgacg-motif binding basic leucine zipper transcription factors mediate blade-on-petiole-dependent regulation of development. Plant Physiol. 180, 937-951. doi: 10.1104/pp.18.00805

Wang, Y., Yao, Q., Zhang, Y., Zhang, Y., Xing, J., Yang, B., et al. (2020). The role of gibberellins in regulation of nitrogen uptake and physiological traits in maize responding to nitrogen availability. Int. J. Mol. Sci. 21, 1-21. doi: 10.3390/ijms21051824.

Wu, K., Wang, S., Song, W., Zhang, J., Wang, Y., Liu, Q., et al. (2020). Enhanced sustainable green revolution yield via nitrogen-responsive chromatin modulation in rice. Science 367:eaaz2046. doi: 10.1126/science.aaz2046

Wulf, K. E., Reid, J. B., and Foo, E. (2019). Auxin transport and stem vascular reconnection-has our thinking become canalized? Ann. Bot. 123, 429-439. doi: $10.1093 / \mathrm{aob} / \mathrm{mcy} 180$
$\mathrm{Xu}$, P., and Cai, W. (2019). Nitrate-responsive OBP4-XTH9 regulatory module controls lateral root development in Arabidopsis thaliana. PLoS Genet. 15:e1008465. doi: 10.1371/journal.pgen.1008465

Yan, M., Pan, G., Lavallee, J. M., and Conant, R. T. (2020). Rethinking sources of nitrogen to cereal crops. Glob. Chang. Biol. 26, 191-199. doi: 10.1111/ gcb.14908

Zadoks, J. C., Chang, T. T., and Konzak, C. F. (1974). A decimal code for the growth stages of cereals. Weed Res. 14, 415-421. doi: 10.1111/j.1365-3180.1974. tb01084.x

Zeng, X. P., Zhu, K., Lu, J. M., Jiang, Y., Yang, L. T., Xing, Y. X., et al. (2020). Long-term effects of different nitrogen levels on growth, yield, and quality in sugarcane. Agronomy 10:353. doi: 10.3390/agronomy10030353

Zhang, W., Wu, L., Ding, Y., Yao, X., Wu, X., Weng, F., et al. (2017). Nitrogen fertilizer application affects lodging resistance by altering secondary cell wall synthesis in japonica rice (Oryza sativa). J. Plant Res. 130, 859-871. doi: 10.1007/s10265-017-0943-3

Zhang, J., Zhou, Z., Bai, J., Tao, X., Wang, L., Zhang, H., et al. (2020). Disruption of MIR396e and MIR396f improves rice yield under nitrogen-deficient conditions. Natl. Sci. Rev. 7, 102-112. doi: 10.1093/nsr/nwz142

Zheng, Z. L. (2009). Carbon and nitrogen nutrient balance signaling in plants. Plant Signal. Behav. 4, 584-591. doi: 10.4161/psb.4.7.8540

Conflict of Interest: The authors declare that the research was conducted in the absence of any commercial or financial relationships that could be construed as a potential conflict of interest.

Copyright (c) 2021 Souza and Tavares. This is an open-access article distributed under the terms of the Creative Commons Attribution License (CC BY). The use, distribution or reproduction in other forums is permitted, provided the original author(s) and the copyright owner(s) are credited and that the original publication in this journal is cited, in accordance with accepted academic practice. No use, distribution or reproduction is permitted which does not comply with these terms. 